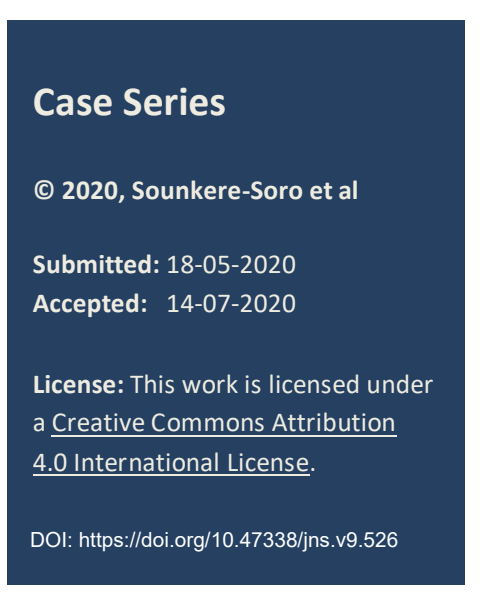

\title{
Colonic atresia in neonates: Management dilemma in a developing country
}

Moufidath Sounkere-Soro, * Jean-Baptiste Yaokreh, Yapo Guy Serge Kouame, Helen Audrey Thomas, Samba Tembely, Eric Koffi, Thierry Odehouri-Koudou, Dibi Bertin Kouame, Ossenou Ouatarra

Department of Mother and Children (Pediatric Surgery), University Hospital Centre, Yopougon CÔTE D'IVOIRE

Correspondence*: Sounkere-Soro Moufidath, M.D., Department of Mother and Children (Pediatric Surgery), University Hospital Centre, Yopougon Côte d'Ivoire. E-mail: s.moufidath@yahoo.fr

\section{KEYWORDS \\ Colonic atresia \\ Colostomy \\ Newborn}

\section{ABSTRACT}

Background: Colonic atresia is one of the rarest causes of congenital intestinal obstructions. Its diagnosis is difficult, but prenatal investigations can improve it. The management of colonic atresia is not codified and depends on the resources available and surgeon's experiences.

Case Series: We report three neonates presented with intestinal obstruction. At surgery, the diagnosis of colonic atresia was made. Two neonates were managed with an initial stoma. One baby died intraoperatively.

Conclusion: Management of colonic atresia is challenging in a developing country. Staged management with a stoma as initial procedure suits best to such settings.

\section{INTRODUCTION}

Colonic atresia (CA) is one of rarest causes of congenital intestinal obstructions, offering a neonatal surgical challenge. [1] It represents 1.8 to $15 \%$ of all intestinal atresia with a reported incidence of approximately $1 / 40000$ live births. [2,3] Its etiology is not clearly defined but some hypotheses have been postulated like mesenteric vascular compromise or genetic mechanism.[4,5] This anomaly may be isolated or part of a poly malformation syndrome. There is no clear guideline regarding the management in literature. Because of its rarity, large series have not been reported in the literature concerning management and predictors of outcome.

We are hereby reporting three cases of CA by exposing the difficulties of preoperative diagnosis and management in limited resource setting.

\section{CASE SERIES}

Case 1: A 3-day full-term baby female presented with emesis and failure to pass stool since birth, was transferred to our pediatric surgery department. There was no history of drug administration or exposure of any known teratogenic agents during pregnancy. The newborn was delivered vaginally at term with a birth weight of $2850 \mathrm{~g}$. On examination, she was febrile $\left(\mathrm{T}=38^{\circ} \mathrm{C}\right)$ tachycardiac $(170 / \mathrm{min})$, and tachypneic (70/min). Clinical examination revealed distended abdomen. An imperforate anus with an obvious anal dimple on perineal inspection, with poorly developed gluteal muscle and presence of two perineal openings: urethral and vaginal without visible fistula. She had normal female external genitalia. No other physical abnormalities were noted. Abdominal x-rays showed extensive bowel dilatation. Work-up for associated anomalies was unremarkable. Exploration revealed intact gastrointestinal system from proximal stomach to the ascending colon. However, distal to the transverse colon existed a blind-ending colon with a massive dilatation of proximal colon followed by multiple CA (type IV) (Fig. 1). Transverse end colostomy. She was discharged home in good conditions. At 8 months of age, Abdomino-PSARP was performed to establish colonic continuity with anus. Postoperative recovery was uneventful.

Case 2: A 2-day-old full-term male (birth weight: 2550 ) baby was born (SVD) to a 16-year-old mother. He was admitted in our department 48 hours after birth, with abdominal distention, bilious vomiting and failure to pass meconium since birth. The maternal history revealed a hemoglobinopathy $\mathrm{AC} \quad(\mathrm{A}=70 \%$ $\mathrm{C}=30 \%$ ). Prenatal examination was unremarkable. No drugs or infectious exposure was documented during pregnancy. On examination, the child was irritable with excessive crying. Pulse rate was $150 / \mathrm{min}$, respiratory rate $48 / \mathrm{min}$, and temperature was $37^{\circ} 4 \mathrm{c}$. Ab- 
dominal examination revealed distended abdomen, with increased peristaltic activity. Abdominal x-ray showed distended bowel and air fluid level. Workup for associated anomalies was unremarkable. Surgical exploration revealed a colonic atresia (type III) of splenic flexure. Colostomy was performed. Colic continuity was restored 6 months later with resection of a segment of the proximal dilated colon and end to end anastomosis. Follow up was uneventful.

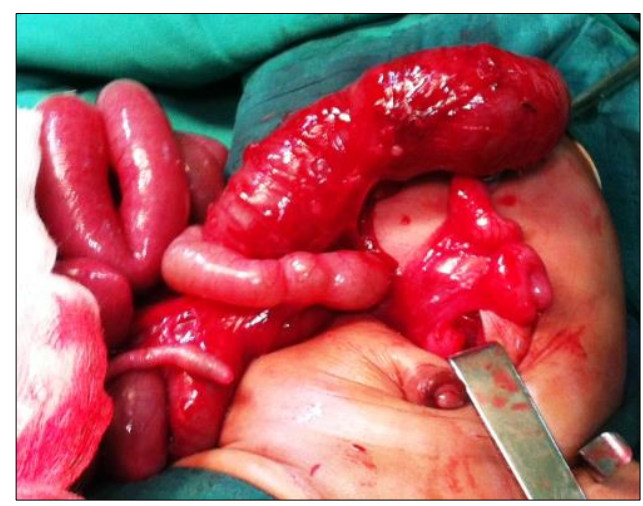

Figure 1 : Showing blind ending transverse colon with multiple atresia of distal colon.

Case 3: A 2-day-old female neonate was admitted for bilious vomiting, progressive abdominal distension and delayed meconium passage. There was no history of drug administration or exposure of any known teratogenic agents during pregnancy. The newborn was born by vaginal delivery at term with a birth weight of $3700 \mathrm{~g}$. On examination she was icteric and febrile $\left(\mathrm{t}^{\circ}=40^{\circ} \mathrm{C}\right)$ with tachypnea $(68 / \mathrm{min})$. The heart rate was $162 \mathrm{~b} / \mathrm{min}$. Abdomen was moderately distended. Rectal examination revealed an empty rectum. Abdominal $\mathrm{x}$-rays showed multiple gas fluid levels in the upper abdomen without any visible gas shadow in the pelvis. Workup for associated anomalies was unremarkable. On exploratory laparotomy, type I atresia of the descending colon was confirmed. Resection of the diaphragm was performed with transverse closure. The baby had a hemodynamic event intraoperatively and succumbed.

\section{DISCUSSION}

Etiology of this anomaly remains uncertain. In-utero vascular accidents in the early gestation is the most likely accepted theory. Colonic volvulus, intussusception, incarceration, and strangulation of internal hernias in-utero are also the probable etiological factors. Failure of recanalization after the solid cord stage as in duodenal atresia is also considered to be the cause of colonic atresia.[6] New research explains the role of genetic defect in occurring intestinal atresia. [5] The rarity of CA, and the difficulty to diagnose it, impose the suspicion especially when facing a case of low intestinal obstruction with failure to pass meconium. According to Zhou's study, there is evidence that $2 / 3$ of all
CA cases are not diagnosed preoperatively. [1] However antenatal diagnosis is possible. Prenatal diagnosis has a significant impact on management and prognosis of CA by carrying out the delivery in a hospital with an adequate technical platform allowing immediate treatment.

Prenatal scan may show dilatation of intestinal loops (more than $15 \mathrm{~mm}$ in length and $7 \mathrm{~mm}$ in diameter) suggestive of fetal bowel obstruction. There is an intraluminal bowel echogenicity difference on prenatal ultrasounds, based on a gray scale, between the small and large intestines which could guide the level of obstruction.[7] However ultrasound has several limitations and is mainly operator dependent. Fetal MRI may help diagnose CA antenatally. The preoperative diagnosis of colonic atresia can be made with help of contrast enema which opacify the microcolon with abrupt interruption of colonic imaging (abrupt halt or hook sign). [8] Any newborn with a suspicion of colonic atresia clinically and on plain radiograph should have a contrast enema to delineate the unused colon. In our study the diagnostic of CA was difficult. The signs were unclear and masked by the associated malformations. All CA were diagnosed intraoperatively. One case of CA (type IV) was associated with anorectal malformation without fistula, which is very uncommon (less than $5 \%)$.

In case of anorectal malformation CA must be suspected when no meconium is encountered during initial anorectoplasty. [9] In some studies, CA has been associated with other anomalies, including omphalocele, gastroschisis, exomphalos, vesicointestinal fistula, imperforate anus and Hirschsprung's disease. [10]

There is no consensus as to the management of CA. The decision of primary anastomosis or ostomy is mostly based on condition of the baby, and expertise of the surgeon and the postoperative care of the center. We preferred a colostomy in 2 cases (as first case also had anorectal malformation) to decrease the duration of anesthesia and to avoid neonatal mortality. In the third case, we preferred to excise the colonic diaphragm but unfortunately the baby succumbed to intraoperative hemodynamic instability.

In conclusion, CA is one of the rarest causes of intestinal obstruction in neonates in our practice. Preoperative diagnosis is difficult. Management by initial colostomy followed by secondary restoration of digestive continuity allows us to save the neonate in low resource setting.

\section{Acknowledgements: Nil \\ Conflict of Interest: None declared}

Source of Support: Nil

Consent to Publication: Author(s) declared taking informed written consent for the publication of clinical photographs/material (if any 
used), from the legal guardian of the patient with an understanding that every effort will be made to conceal the identity of the patient, however it cannot be guaranteed.

\section{REFERENCES}

1. Zhou JL, fang YL, Tian S, Zhu XC, Ge WP. Radiological feature of colonic atresia. Arch Dis Child Fetal Neonat Ed. 2018; 103:f263.

2. Singh V, Pathak M. Congenital neonatal intestinal obstruction: retrospective analysis at tertiary care hospital. J Neonat Surg. 2016; 5:49.

3. Karnak I, Ciftci AO, Senocak ME, Tanyel FC, Buyukpamukcu N. Colonic atresia: surgical management and outcome. Pediatr Surg Int. 2001;17: 631-5.

4. Atarraf K , Shimi A, Lachqar M , Harandou M, Bouabdallah Y. Colonic atresia: report of two cases. Pan Afr Med J. 2010; 7:9.

5. Fairbanks TJ, Kanard RC, Del Moral PM, Sala FG, De Langhe SP, Lopez CA, et al. Colonic atresia without mesenteric vascular occulsion. The role of fibroblast growth factor 10 signalling pathway. J Pediatr Surg. 2005; 40:390-6.
Author Contributions: Author(s) declared to fulfil authorship criteria as devised by ICMJE and approved the final version.

6. Saxonhouse MA, Kays DW, Burchfield DJ, Hoover R, Islam S. Gastroschisis with jejunal and colonic atresia and isolated colonic atresia in dichorionic, diamniotic twins. Pediatr Surg Int. 2009; 25:437-9.

7. Goruppi I, Arévalo S, Gander R, Molino JA, Oria M, Carreras E, et al. Role of intraluminal bowel echogenicity on prenatal ultrasounds to determine the anatomical level of intestinal atresia. J Matern Fetal Neonatal Med. 2016; 30:103-8.

8. Patoulias I, Feidantsis T, Doitsidis C, Mitroudi M, Kalogirou MS, Patoulias D. Early diagnosis and surgical intervention untie the Gordian knot in newborns with colonic atresia: report of two cases and review of the literature. Folia Med Cracov. 2019; 59:67-79.

9. Goodwin S, Schlatter M, Connors R. Imperforate anus and colon atresia in a newborn J Pediatr Surg. 2006; 41:583-5.

10. El-Asmar KM, Mohammed A, El-Kassaby AA, Soliman MH, El-Behery MM. Colonic atresia: association with other anomalies. J Neonat Surg. 2016; 5:47. 